\title{
Authorship error
}

In a recently published paper entitled, "Impact of the systemic immune-inflammation index for the prediction of prognosis and modification of the risk model in patients with metastatic renal cell carcinoma treated with first-line tyrosine kinase inhibitors," (Citation: Teishima J, Inoue S, Hayashi T, et al. Can Urol Assoc J 2020;14(11):E582-7. http://dx.doi.org/10.5489/ cuaj.6413), Akio Matsubara, MD, PhD, was mistakenly listed as an author.

Please visit https://cuaj.ca/index.php/journal/article/view/6413/4682 for a corrected version of the full manuscript. CUAJ regrets the oversight and apologizes for any inconvenience. 